\title{
LECTOR Y LECTOR IMPLÍCITO EN CAMPO DE AGRAMANTE DE JOSÉ MANUEL CABALLERO BONALD
}

\author{
AnTonio UnZUÉ UnZUÉ \\ aunzue@xtec.cat
}

\section{RESUMEN}

La publicación en 1992 de la novela Campo de Agramante de Caballero Bonald abre una nueva etapa en la producción narrativa del escritor jerezano. Desde la perspectiva de la recepción, en este artículo se analiza la propuesta de lectura inserta en el relato, así como algunas de las orientaciones que configuran el horizonte de expectativas en el proceso de lectura. Todos estos factores inciden en una disposición más activa por parte del lector ante un texto que desafía la recepción narrativa convencional.

PALABRAS ClAVE: Lector implícito, horizonte de expectativas, Caballero Bonald, novela, ficción.

\section{RÉSUMÉ}

La parution en 1992 du roman Campo de Agramante de Caballero Bonald ouvre une nouvelle étape dans la production narrative de l'écrivain de Xérès. D'accord avec l'école de la réception, l'on analyse dans cet article le contrat de lecture proposé dans ce roman et aussi certains traits de l'horizon d'atteinte au moment du procès de lecture. Toutes ces données demandent une attitude plus active de la part du lecteur en face d'un texte qui défie la réception narrative conventionnelle.

Mots CLÉs: Lecteur implicite, horizon d'atteinte, Caballero Bonald, roman, fiction. 
LA OBRA DESDE LA PERSPECTIVA DE LA RECEPCIÓN

En 1992 José Manuel Caballero Bonald publica su quinta novela, Campo de Agramante, obra en la que un narrador en primera persona refiere los trastornos sensoriales que le permiten prever acontecimientos por vía auditiva. El título escogido por el autor para su novela, de resonancias clásicas, remite a la idea de confusión, esa misma perplejidad que la obra transmite al lector.

Pero, ¿qué hace de este relato una narración tan particular y desconcertante? ¿En qué sentido sorprende al lector atento de Caballero Bonald? ¿En qué medida le exige una participación diferente en el proceso de lectura? ¿Qué hace de esta novela, en definitiva, un relato singular en la producción del escritor jerezano?

En Campo de Agramante, el lector se enfrenta a una historia en la que se intensifican algunos aspectos de las novelas precedentes, como el interés por los aspectos paradójicos de la intimidad. Al mismo tiempo, pierden relevancia otros elementos narrativos más directamente conectados con la caracterización del universo social presente en las novelas anteriores. Para el lector, En la casa del padre (1988), la novela precedente, funciona como el cierre de un ciclo centrado, entre otros aspectos, en el análisis de la sociedad gaditana.

A este respecto, los teóricos de la estética de la recepción insisten en la importancia de la lectura como acto creativo, siguiendo la concepción del lector como coautor de la obra. Con ello, relativizan las prerrogativas auctoriales sobre el texto. Desde su perspectiva, cualquier creación literaria funciona con una cierta autonomía en relación al autor: una vez llega al lector, la obra es objeto de un proceso interpretativo en el que intervienen numerosos factores: unos, internos al texto y otros, marcados por el horizonte de expectativas dominante.

Así, la contribución del lector resulta fundamental para la configuración del sentido final de la obra. No obstante, este proceso no es arbitrario, sino que viene determinado por las estructuras textuales que orientan el acto interpretativo. Esta disposición textual es lo que se conoce como lector implícito, es decir, la propuesta de lectura inserta en la obra (ISER, 1972), cuyas indeterminaciones debe solventar el receptor empírico. La dinámica apelativa del texto fuerza la intervención del lector, que se ve obligado a culminar el proceso literario con la interpretación de la obra (ISER, 1970).

Así pues, frente al lector real, es decir, la persona que pone en juego su competencia literaria, se entiende como lector implícito el conjunto de estructuras textuales que determinan la interpretación verificada en el momento de la lectura. Esta disposición textual se compone de elementos procedentes de los ámbitos sintáctico, semántico y pragmático de la novela, si nos ajustamos a un modelo semiótico de análisis (BOBES NAVES, 1993; ROMERA CASTILLO, 1995).

\section{LECTOR IMPLÍ́CITO EN CAMPO DE AGRAMANTE}

El plano sintáctico de la novela conforma un nivel básico en la interpretación de la obra. En él concurren aspectos medulares como las secuencias, los personajes, el tiempo y el espacio, elementos todos ellos fundamentales en el género narrativo. Su caracterización, por tanto, resulta necesaria para la imagen del lector implícito. 
En cuanto a la secuencia básica, la novela plantea una historia de búsqueda personal protagonizada por un personaje afectado por serios trastornos psicológicos. En este sentido, el armazón estructural de la novela se aleja notablemente por su contenido íntimo de la dimensión social de las novelas anteriores. En todas ellas se observa la presencia de algunos personajes destacados cuya intimidad alcanza cierto desarrollo, pero el conflicto se establece normalmente entre el individuo y la sociedad.

Caballero Bonald cierra con su cuarta novela un ciclo narrativo centrado en los conflictos socioeconómicos de su tierra andaluza. Sin abandonar ese mismo espacio, reorienta ahora su interés hacia las anomalías psicofísicas de un personaje en proceso de búsqueda personal. En esta secuencia se distinguen tres etapas. Primero, una función de desconcierto, en la cual el protagonista da cuenta de los síntomas que le afectan. Sigue posteriormente una función de búsqueda, que incluye la visita a diversos especialistas, el recurso a tratamientos alternativos, la investigación sobre el tema, la dedicación más intensa al trabajo y dos decisiones fundamentales: la consignación en un cuaderno del proceso de recuperación y el traslado al piso de Cerro Falón. La escritura aparece, por tanto, como una herramienta terapéutica y el abandono de la casa familiar se presenta como el deseo de alcanzar una autonomía personal indispensable. Por último, cierra esta secuencia una función de aceptación personal, en la que el narrador toma conciencia de sus limitaciones neurológicas, descubre en la dependencia materna el origen de sus conflictos, decide volcarse en empresas de carácter personal (como la de Apolonio) y, una vez asumida su situación, opta por abandonar la escritura de su cuaderno de notas.

En cuanto a los personajes, destaca la figura del protagonista, un joven enfermizo que adopta el papel de narrador. Su caracterización constituye un elemento básico del relato, donde se ilustran los numerosos síntomas de su enfermedad: vértigos, percepciones extraordinarias, hiperestesia, fallos de la memoria, alteraciones del sueño:

Todos los síntomas tenidos como propios de la insuficiencia circulatoria cerebral, coincidían de hecho con los míos: trastornos del sueño, pérdida de la memoria, inestabilidad emocional, síndromes vertiginosos, cefaleas vasculares. (1992: 90)

Junto con todas estas anomalías, el lector queda informado también de la ideología, las aficiones, las lecturas y las obsesiones del personaje. Asimismo, la función de narrador adoptada por el protagonista implica además la presencia de numerosas reflexiones acerca de la propia escritura del relato y de su carácter terapéutico:

Si no hubiese sido porque anteanoche volví a atravesar por una experiencia muy parecida a la que viví en aquella ocasión, tampoco se me habría ocurrido ir anotándolo todo en este cuaderno. Pensé que, al menos, así me sería más fácil cotejar en su día fechas y episodios y engranar, llegado el momento, ese mecanismo de referencias que tal vez me explicarían mejor lo que estaba pasando, suponiendo que lo que estaba pasando fuese algo distinto a una aprensión obcecada. (1992: 20)

Por otra parte, se trata de un personaje cuyo nombre no se indica. Un sangrador lo llama «el buscapistas» (1992: 51), denominación que el narrador oye casualmente sin acabar de entenderla. Marcela, por su parte, se refiere a él como «don Misterios» (121) en una carta que acompaña la entrega del aparato para las cervicales. Ambas expresiones su- 
brayan el carácter obsesivo del personaje, el retraimiento y concentración en su vida interior.

Esta situación, en la que se mezclan trastornos físicos con alteraciones psicológicas, permite entender la importancia en el relato de las percepciones extraordinarias. De hecho, el relato comienza con la audición anticipada de la caída del espejo materno y la captación del grito de la suicida antes de producirse, pero su presencia menudea en la narración. Así, el protagonista refiere audiciones inverosímiles, como el jadeo femenino durante el viaje en barca, la percepción de ultrasonidos o la escucha anticipada del ruido de la quilla de Orozco. Avanzado el relato, el narrador acaba desconfiando de sus referencias sensoriales, convencido de su recuperación.

Las alteraciones psicológicas desarrollan otras posibilidades, como la intuición de la visita de Javier Dopingo a Apolonio, la presencia insistente de ruidos y ecos en el piso de Cerro Falón, el miedo patológico relacionado con sonidos diversos, el acoso obsesivo de las voces, la escucha injustificada del timbre del piso, la repentina euforia que anula las caídas del estado de ánimo, el pánico irracional ante el gusano azul del vibrador, la percepción anómala de sonidos, la audición extraordinaria de los cristales rotos, la experiencia aterradora de la mano atrapada en el vacío o la percepción inverosímil de la polea de un pozo. Todas estas anormalidades parecen consecuencia, según el protagonista, de una disfunción circulatoria, pero resultan muy desconcertantes para el lector, que no acaba de saber cómo debe interpretarlas.

Otro elemento característico del protagonista es la indicación reiterada de algunas obsesiones, entre las cuales destaca particularmente el sueño del bosque en llamas, que a veces se limita a la indicación de un lugar opresivo sin salida, mientras que en otras ocasiones incorpora la intervención materna y su intento de rescatarlo y subirlo a la barca. Más adelante reaparece el sueño, pero el narrador echa en falta en él algún dato, lo cual no deja de ser inquietante. En fragmento posterior, el sueño incorpora otra variante, el cuerpo de la madre. La evocación del bosque en llamas se presenta también en estado de vigilia. Finalmente, el personaje parece subrayar la conexión entre el sueño del bosque ardiendo y la figura materna, al situar su aparición inicial en el lejano momento en que acabaron las excursiones en tren con la madre. Una de las anotaciones finales acaba revelando el significado del sueño, asociándolo indisolublemente con la figura materna:

Vislumbré en un sucinto fogonazo la extensión del bosque que ardía obstinadamente en mis sueños, y entonces, de la manera más simple, descubrí lo que nunca se me había manifestado más que a través de indicios defectuosos: yo estuve de niño con mi madre, compartiendo por primera vez su jubilosa adhesión corporal, en ese bosque del sueño, y ese bosque era la misma pineda ahora calcinada a la que me llevó un día tío Leonardo y en la que se inició todo lo que ha venido ocupando porfiadamente mi memoria. (1992: 297)

Al margen de esta presencia recurrente del bosque en llamas, que remite finalmente a su dependencia respecto de la madre, el protagonista refiere el temor a que el sueño de las habitaciones escritas constituya un aviso del retorno de las irregularidades sensoriales. El narrador queda caracterizado también por otras fijaciones, como de algunas piezas de madera exótica como talismanes: la tabla de palo-cajá, los fragmentos de caoba y baobab o el trozo de calambar regalado por Marcela. 
Alrededor del narrador giran los demás personajes de la historia. Su estructuración respeta ciertos ámbitos naturales: la familia, limitada a la madre, el padre ausente y el tío; los amigos, entre los cuales destacan figuras como Apolonio, don Maxi, Orozco, Marcela y Elvira, con quienes, sin embargo, no llega nunca a franquearse del todo; por último, el resto de los personajes. Entre ellos pueden distinguirse médicos, curanderos, personajes de otras novelas, autores citados y una amplia lista de figuras extravagantes. En su presentación destaca una norma curiosa: cuanto menor es la importancia del personaje en la historia, más detallada es su descripción.

Por otra parte, la mirada del narrador se recrea en la captación de personajes sorprendentes, en el límite incluso de lo verosímil y de la marginalidad. Así, en el bar adonde acude, entra un muchacho de lo más curioso, con cierto parecido con una libélula, al que le faltan los párpados inferiores. Su presencia introduce alguna otra nota sorprendente:

-No te fíes de esos — me susurró sibilinamente el muchacho del perfil de libélula (...).

- Tú ya te estás callando hasta nueva orden - decretó el que vendía maquetas - ¿Enterado?

El muchacho no sólo se calló sino que se fue hacia la puerta, emitió una especie de reclamo de mirlo en celo y desapareció sin más circunloquios. Llevaba en la cara el ceño hierático de quien no hace preguntas porque tampoco espera ninguna respuesta. (1992: 272-273)

Llama la atención en esta historia lo reducido de la familia. Frente a las novelas precedentes, en las que alcanza notable importancia el clan familiar, aquí se observa la fragmentación del grupo inicial con la imagen del padre difunto. De ahí procede la enfermiza relación entre madre e hijo, alterada posteriormente por la irrupción de tío Leonardo. En consecuencia, el eje de la historia se centra en la compleja red de sentimientos vividos en el seno familiar por el protagonista. Por eso, cuando finalmente el narrador proyecta seguir su camino asociándose con Apolonio, no deja de sentirse, en cierta medida, como un traidor:

No es que tuviese mis dudas sobre todo ese proyecto que habíamos discutido concienzudamente Apolonio y yo, calculando al máximo los costes y beneficios de la grada y el dique seco, pero se me había acentuado la impresión de no estar comportándome bien, algo parecido a ese malestar que perdura después de haber recurrido a alguna maledicencia para herir a alguien. Incluso llegué a suponer que estaba a punto de conculcar un pacto tácitamente sellado con mi madre desde mucho antes de que ella también lo quebrantara casándose con tío Leonardo. (1992: 278)

Las relaciones entre los personajes ofrecen numerosas perspectivas, todas ellas planteadas en torno a la figura central del narrador. En efecto, es el protagonista quien encuentra asociaciones, como sucede entre su madre y Marcela, entre don Maxi, Orozco y Apolonio; contrastes, como se aprecia entre el físico de Marcela y el de Elvira; relaciones de dependencia, como la central entre el protagonista y su madre. Asimismo, se observa la contraposición entre el tratamiento caricaturesco de muchos personajes secundarios, como Emeterio Bidón y Lucrecia, y la valoración positiva de otros, como Apolonio o los Masteleros. También se aprecia el juego de contrapunto entre figuras 
como el librero republicano y su vecino franquista. En definitiva, el juego constructivo configurado por las relaciones de los personajes conforma una tupida red en cuyo centro aparece la figura desconcertante del narrador.

El tiempo constituye un elemento destacado en esta novela, que el narrador presenta como unas enmarañadas memorias. Todo el relato es el resultado de sus anotaciones, realizadas con la intención de objetivar su experiencia personal. De este modo, la afición por la escritura surge como un deseo de garantizar la continuidad de la memoria en un contexto especialmente vulnerable. La relectura de las notas permite la constatación de errores, como éste referido a Elvira:

De lo que no me acordé entonces - sino ahora, mientras escribo - es de mi inexplicable confusión al referirme en su día a esa muchacha, cuya supuesta comparecencia en el bar quedó registrada en un momento y en un sitio que no eran en absoluto los que juiciosamente le correspondían. (1992: 110)

La complejidad del relato se relaciona con el hecho de que se plantea como una serie de anotaciones sucesivas, lo cual se opone a la perspectiva final única de los textos estrictamente memorialísticos. Desde el punto de vista absoluto, la historia toma como eje el tiempo contemporáneo a la publicación del relato, como revela alguna referencia a la Expo de Sevilla. A este respecto, sigue la misma línea que el resto de narraciones del autor, a excepción de la relativa deriva mítica de Ágata ojo de gato.

La extensión de la historia narrada es confusa, pues los límites temporales, si bien presentan algunas referencias fijas, como los primeros síntomas vividos en la adolescencia, no acaban de concretarse. Las elipsis temporales son frecuentes y no se indica siempre su extensión. A este respecto, las deficiencias del narrador marcan temporalmente el relato. Se trata, no obstante, de un elemento de verosimilitud y de adaptación a la dinámica introspectiva de esta historia. El tiempo psicológico es, en definitiva, su referencia básica. En efecto, en Campo de Agramante se desarrolla con más plenitud un rasgo, la conciencia temporal, presente en novelas anteriores a través de personajes como Miguel, de Dos días de setiembre (1962), o José Daniel, de En la casa del padre (1988).

En cuanto al orden, la narración sigue una disposición cronológica, si bien el narrador acaba percibiendo el tiempo más como una secuencia circular que como una estructura lineal, aspecto que quiebra la linealidad del relato convencional y cuestiona las expectativas del lector:

Todo estaba aparentemente en orden. Pero todo estaba remontando también un atajo que conducía a algún enigmático lugar de procedencia. Lo notaba por un aturdimiento, un raro centelleo de la memoria. Y eso, debido a una razón todavía incierta, no me hacía augurar nada bueno. (1992: 291)

Asimismo, el desarrollo temporal se ve alterado por frecuentes retrospecciones, al hilo de las evocaciones del narrador. La propia escritura se plantea, pese al aparente avance lineal, como una serie de retrospecciones sucesivas, que afectan al pasado del narrador y al de otros personajes. Esta estructura retrospectiva, que no puede desligarse de la consideración de la escritura como terapia, exige el concurso de la analepsis. Las citas que 
pueden aducirse a este respecto son abundantes. Ya en el prólogo, el narrador relaciona una reciente anomalía con los trastornos sensoriales padecidos en su adolescencia:

Eran los últimos días de abril, pronto hará nueve años. Si no hubiese sido porque anteanoche volví a atravesar por una experiencia muy parecida a la que viví en aquella ocasión, tampoco se me habría ocurrido ir anotándolo todo en este cuaderno. Pensé que, al menos, así me sería más fácil cotejar en su día fechas y episodios y engranar, llegado el momento, ese mecanismo de referencias que tal vez me explicarían mejor lo que estaba pasando (...). (1992: 20)

Abundan, asimismo, las referencias a la discontinuidad de la escritura, con un doble efecto: por una parte, subrayan así la distancia entre el tiempo del enunciado y el de la enunciación; por otra, obligan al narrador a recuperar en forma de resumen lo más sustancial del tiempo transcurrido. La cita siguiente es un buen ejemplo de esto:

Para mejor enlazar con lo que dejé escrito hace unos dos meses, creo que debería referirme, por lo menos, a dos llamativas anécdotas intermedias: la consumación del pacto erótico que me habían propuesto Marcela y Elvira y el accidente de Agustín, a quien la máquina regruesadora le sesgó el dedo gordo de la mano derecha. (1992: 187-188)

El narrador sigue, por tanto, un proceso discontinuo de redacción, según la necesidad psicológica de recurrir a esta terapia, motivo que justifica el abandono temporal de la escritura.

Otro tipo de alteración temporal relevante en este relato es la prolepsis o anticipación narrativa, cuya importancia se plantea en dos planos: en el desarrollo del relato y en la enfermedad del protagonista. Así, por una parte, durante la narración abundan referencias que orientan (o despistan) al lector en su interpretación mediante pequeños adelantos. Ya en el prólogo, se insinúa la futura unión de tío Leonardo y la madre del narrador. Un poco más adelante, el propio narrador sugiere al lector la interpretación de la historia y justifica la escritura como un mecanismo de referencias para conocerse a sí mismo. Avanzando en el relato, destaca un ejemplo de anticipación: la imagen de Orozco muerto se antepone en la secuencia al relato de su descubrimiento en la playa. Incluso el narrador, a modo de hipótesis, adelanta también el desenlace de su propia historia: su curación vendría tras la visita a la curandera de Jédula, quien le prescribiría unos ejercicios de recuperación. En la secuencia séptima de este capítulo, la audición de una conversación verificada en otro sitio le avisa al protagonista del peligro y le permite prever su futuro. El capítulo cuarto arranca de una forma curiosa, anticipando al lector el futuro desarrollo de los hechos o, al menos, una perspectiva verosímil:

Voy a contar algo que no ha ocurrido todavía. Por supuesto que tampoco estoy seguro de que vaya a ocurrir - cada vez estoy menos seguro de más cosas - , pero me tienta adelantarme a esa posibilidad para saber de cierto si lo que escribo ahora se corresponde después exactamente con los hechos reales. (1992: 131)

Se refiere con ello a la paulatina disminución de los síntomas extraordinarios y la vuelta a la normalidad. Conforme se acerca el final de la historia, el protagonista co- 
mienza a desconfiar de su optimismo y temer una recaída en su enfermedad. Esta intuición reaparece poco antes del derrumbamiento de la biblioteca:

Entré en la sala con el ambiguo sentimiento de estar internándome por un pasadizo amorfo y aborrecible cuya salida venía a enlazar sinuosamente con la entrada. (1992: 296)

Por otra parte, además de los adelantos narrativos que, con mayor o menor destreza, maneja el narrador, conviene considerar en este relato las anticipaciones que, como una consecuencia de su enfermedad, padece el protagonista. Aparte las cefaleas o la audición de sonidos a distancia, las anticipaciones auditivas constituyen sus trastornos más destacados. La anomalía que cierra el relato es otra anticipación acústica, con la que el narrador reconoce la pervivencia de sus trastornos, de los que había pensado poder librarse. Su actitud, sin embargo, ha variado: del desconcierto inicial pasa a una especie de lucidez. Cuando, tras contemplar el paisaje desde su terraza, se dispone a volver a la sala, oye «un estrépito que, en ese sigiloso tramo del amanecer, resonó justamente como si se derrumbara todo el edificio» (1992: 296). Inmediatamente, el narrador intuye que se trata de una nueva anticipación auditiva, lo que le produce un sentimiento ambiguo de circularidad, pese al cual espera «con absoluta placidez» el desarrollo de los acontecimientos, esto es, el derrumbe de la librería. Todo ello le induce a creer que su recuperación no ha sido sino «un incauto paréntesis de normalidad», con lo cual «el cerco de tantas y tan abstrusas irregularidades acústicas (...) acababa finalmente de estrecharse» (1992:297).

Así pues, la presencia de prolepsis responde a un doble objetivo: la plasmación de las irregularidades psicológicas del protagonista y la graduación del interés narrativo, como corresponde a un personaje progresivamente interesado por el propio proceso de escritura. De modo que las alteraciones de la línea temporal combinan utilidad narrativa y profundización psicológica.

Respecto al ritmo, destaca la presentación escénica, en un deseo del narrador por fijar el recuerdo en todos sus detalles. Así, la secuencia tipo suele engarzarse con la anterior a través de un breve resumen, que luego da paso a la escena central, a menudo dialogada. El conjunto suele cerrarse con una reflexión final del narrador. Por otro lado, desde el punto de vista rítmico, puede señalarse el carácter retardador de las retrospecciones que alteran el hilo del relato, frente a las prolepsis, que aceleran el ritmo interno de la historia. Esta tendencia a la presentación escénica combinada con el resumen es habitual en la narrativa del autor y responde a su gusto por el detalle.

En cuanto a la frecuencia, llama la atención el carácter reiterativo de algunas secuencias, como la imagen del sueño o la tala de Alcaduz, lo cual no puede desligarse de la propia psicología del protagonista. En efecto, se trata de un personaje afectado por una serie de trastornos, entre los cuales destacan las alteraciones del sueño en forma de pesadillas recurrentes, cuya interpretación constituye un desafío para el lector.

En definitiva, el tiempo constituye un factor esencial en este relato, en cuanto que se trata de un elemento clave en el proceso de búsqueda personal del protagonista. Pero se plantea más como un tiempo psicológico que histórico, ya que la atención narrativa se centra en la persona del narrador y sus conflictos. Por otra parte, el tiempo se convierte también en objeto de reflexión, dado el carácter metanarrativo de numerosas secuencias. 
La escritura del protagonista es, pues, la de un supuesto aficionado, no especialmente experimentado en el ejercicio narrativo. Pero funciona como una herramienta para la reflexión sobre la propia enfermedad. Eso le lleva a marcar las diferencias existentes entre el tiempo del enunciado y el de la enunciación, ya que a menudo la percepción de un fenómeno recibe una interpretación posterior diferente de la inicial. Esto se aprecia en frases comunes como esta:

De lo que no me acordé entonces - sino ahora, mientras escribo - es de mi inexplicable confusión (...). (1992: 110)

Este desfase le lleva a veces a dudar de la exactitud de sus percepciones:

No sé si recordé entonces todo eso o supongo ahora que lo recordé. (1992: 262)

Otras veces, el narrador acerca la narración hasta el mismo momento de la escritura:

Pero me he quedado escribiendo hasta tarde y aún no he podido comprobarlo. (1992: 265)

Todo el esquema narrativo, que el protagonista comenta con frecuencia, gira en torno al proceso de recuperación, que parece encaminado al éxito. Sin embargo, la pervivencia de los trastornos rompe ese avance lineal, con un desenlace que remite indefectiblemente al punto de partida.

Asimismo, la mirada atenta del narrador concede una importancia clave al tiempo atmosférico, que a menudo aparece rodeado de valores simbólicos para el personaje y da testimonio de su fina sensibilidad. Algunas referencias estacionales, como la concurrencia de rasgos otoñales, constituye un indicio de nuevas anomalías, en consonancia con el clima desapacible de las escenas de Alcaduz o la Almoraima. Por eso, enseguida el lector interpreta como un aviso las indicaciones sobre el otoño:

El otoño es aquí muy tornadizo y han bastado tres días de lluvia mansa para que rebosen los husillos. (...) El otro día, a la hora se produjo un serio conato de inundación, pues las cloacas vierten en el río y a veces el ímpetu de las mareas vivas puede más que el de bajada de los desagües. (...) Yo había ido a cenar a casa de mi madre (a nuestra casa, quiero decir) y a esa hora la lluvia ya había ido amainando o llevaba trazas de desaparecer, abriéndose algunos claros entre las nubes cárdenas. Pero una humedad interminable, una humedad que parecía provenir de transformación en esponjas de las piedras, penetraba todo lo que tuviese algún resquicio penetrable. Era otra lluvia invisible, asperjada por el tenaz viento de poniente y depositada en cada poro de la piel. (1992: 257-258)

Por último, a pesar del carácter introspectivo de la narración, no faltan numerosas referencias a la historia del siglo XX, con lo cual queda constancia de la ideología y la actitud del protagonista. En una secuencia se plantea la historia de Jerónimo Latiguera, padre de Agustín, un empleado de la serrería. Jerónimo participó en la guerra civil en el frente de Málaga defendiendo la República. Cuando los sublevados tomaron la ciudad, huyó a la sierra de Grazalema. Casi lo atraparon en Ubrique, pero al final el hambre y las heridas le hicieron entregarse. Su muerte, en octubre de 1937 despeñado en Ronda, 
pone de relieve la brutalidad de los vencedores. Todo ello compone una dura crítica de la injusticia de los vencedores. Conviene señalar, a este respecto, el mantenimiento en esta novela de una línea sostenida a lo largo de toda la producción del escritor, dimensión que no falta ni en Ágata ojo de gato (1974), a pesar de la presencia en esa novela de ciertos elementos desrealizadores.

El espacio es otro rasgo fundamental de la sintaxis narrativa. Esta novela de Caballero Bonald plantea, desde el principio, la simultaneidad de dos espacios complementarios: el imaginario y el real, el mundo interior del narrador y Sanlúcar de Barrameda. El propio título, Campo de Agramante, remite al espacio interior del protagonista. El texto preliminar, tomado del Persiles cervantino, recoge la idea de confusión y alteración sensorial que lo atenaza. Los trastornos del narrador (cefaleas, vértigos, ruidos anticipados...) le hacen vivir en estado de confusión, con la sospecha de nuevas alteraciones.

El tratamiento del espacio en esta novela, sin embargo, no difiere en exceso de las obras anteriores. Así, pueden distinguirse tres funciones principales del espacio: la creación de un microcosmos, la presentación metonímica de los personajes y la plasmación de la realidad social e histórica.

El espacio contribuye, efectivamente, a la formación de un mundo narrativo, cuyo centro es la figura del narrador. La novela refleja el marco en que se desenvuelve su vida: la casa familiar y el piso de soltero, los bares de Sanlúcar y los espacios naturales de Doñana, Alcaduz o la Almoraima, las calles de la ciudad y el mundo interior del protagonista. Uno de los elementos más inquietantes para el lector es, particularmente, la extraña convivencia entre el espacio cotidiano y la reiterada irrupción de lo inverosímil. Así, en el Talismán, bar que frecuenta el protagonista, junto con los elementos habituales del establecimiento, el narrador percibe un «nimbo azulenco» (1992: 22) que evoluciona inopinadamente por una parte del mostrador.

En la construcción del microcosmos destaca, por tanto, la subjetividad del narrador, cuya perspectiva da cuenta de los detalles que interesa destacar: los olores, los colores, los gustos. El narrador acostumbra a emplear imágenes sugerentes en la formación del espacio narrativo, reforzando así la importancia de las notas sensoriales y favoreciendo la asociación de valores simbólicos. La sensibilidad del narrador ante la naturaleza constituye un rasgo relevante de la presentación del espacio. A modo de ejemplo, en la siguiente cita se percibe la mezcla de elementos visuales, acústicos y olfativos:

Subí al talud y estuve oteando aquella redonda majestad del mundo. Venía del fondo un silencio adusto y reverencial, como una emanación sigilosa que imponía su observancia a toda aquella rotatoria euritmia en cuyos vértices parecía localizarse el origen de una voz animal que se levantaba de la pineda, trasponía el sotobosque y venía a caer en medio del río. (1992: 203)

Todo ello se verifica en una presentación rítmica que oscila entre la mera mención de un nombre y la descripción detallada, si bien lo habitual es que el relato no quede interrumpido en exceso por los cortes descriptivos.

Por otra parte, el espacio contribuye también a la caracterización de los personajes, particularmente del narrador, que queda vinculado a la naturaleza salvaje de Doñana y las imágenes torturadas de sus sueños. Destaca la querencia del narrador por los espacios exteriores como la sierra del Aljibe, el bosque de la Almoraima, Doñana, el pinar de Al- 
caduz o el ramal de la Torre, aspecto en el cual se puede percibir su deseo de independencia y libertad, el rechazo de las convenciones o constricciones sociales, así como el aprecio por la autenticidad de unas formas de vida amenazadas. El protagonista siente peculiar aprecio también por el barrio portuario, donde todavía pueden verse personajes y oficios tradicionales en armonía con el medio natural. Así pues, la principal referencia del espacio es el protagonista, pero también se observan otras indicaciones metonímicas. Se trata, en definitiva, de un uso habitual en la narrativa del escritor, frecuente ya en relatos anteriores.

Finalmente, como sucede en todas las demás novelas del autor, el tratamiento del espacio permite la incorporación de implicaciones sociales o históricas, que remiten al latifundismo medieval, la guerra civil o la especulación urbanística de los setenta. Esta dimensión histórica es una constante en la obra de Caballero Bonald y no falta en este relato, a pesar del énfasis en las cuestiones psicológicas.

Del análisis de los rasgos sintácticos puede inferirse que Campo de Agramante se presenta como una novela desconcertante: frente a la presentación realista del marco principal, el proceso de búsqueda emprendido por el protagonista entra en contacto con lo inverosímil, poniendo así en cuestión los límites de la realidad. Esta frontera de la realidad incluye numerosos personajes y situaciones que producen perplejidad en el lector y desafían el código de lectura realista. La novela propone, por tanto, un pacto de lectura diferente del tradicional y el receptor deberá reajustar sus criterios sobre la marcha.

El lector implícito queda configurado también por los elementos semánticos del relato, que dependen de la figura central del narrador. Esta instancia básica de la novela confiere significado a la historia a través de sus relaciones con el lenguaje y con la referencia.

Por lo que respecta al primer aspecto, a las relaciones entre el narrador y el lenguaje, conviene destacar la importancia de los datos lingüísticos de la voz narrativa, el juego entre discurso interior y exterior, y la distancia del narrador ante el lenguaje de los demás personajes y su propio discurso. Frente a la presencia de diversos narradores en las novelas anteriores, en ésta la instancia narrativa queda reducida a una sola voz dominante. De ahí la importancia de las indicaciones de primera persona, las referencias adverbiales que toman como centro al narrador, el juego verbal que alterna el tiempo del enunciado y el de la enunciación, el pasado y el presente.

Conviene subrayar oportunamente la circunstancia de que la labor narrativa, tal como se plantea en esta novela, supone un paulatino desplazamiento del tiempo de la enunciación. Así se aprecia en el propósito básico del relato, que consiste en anotar las incidencias relacionadas con la enfermedad del narrador según se van produciendo. La escritura se convierte, por tanto, en un elemento terapéutico, consistente en la fijación de los datos para combatir el olvido y la confusión. Sin embargo, la apariencia de relato autobiográfico, relacionada con la incidencia en la vida interior del protagonista, queda cuestionada por la discontinuidad del tiempo de la enunciación y la consiguiente falta de perspectiva única y final sobre la experiencia. A esto se añade que el narrador reconoce la manipulación de las notas originales en una revisión posterior:

El hecho de haber emprendido no hace mucho la martirizante tarea de revisar todo lo que he venido escribiendo, así parece corroborarlo. Hasta he llegado a corregir los pasajes más des- 
lavazados y farragosos del texto, suprimiendo torpezas y reiteraciones expositivas y dándome cuenta, además, que ni siguiera aproveché con una mínima pericia el recurso de la prolepsis en mi manera de resolver la continuidad de la historia. (1992: 257)

Por otra parte, en la novela predomina el discurso interior del personaje, cuya voz monopoliza casi el espacio narrativo. Sin embargo, el deseo de fidelidad en la evocación explica la frecuencia de secuencias dialogadas, construidas en su forma convencional o, en ocasiones, manipuladas mediante el resumen, el estilo indirecto o el estilo indirecto libre. Una de las escenas destacadas del relato es aquélla en que Marcela explica al protagonista lo sucedido en torno a la muerte de Orozco. La secuencia comienza en estilo directo, con unas breves réplicas dialogadas, para pasar posteriormente al resumen, como se aprecia en expresiones como «según su versión, ella y Elvira...» (1992: 281). El resumen se complementa ocasionalmente con alguna referencia en estilo indirecto. De este modo, la secuencia evita un desarrollo excesivamente moroso y agiliza la trascripción de la entrevista.

La distancia entre el discurso narrativo y el discurso de los personajes caracteriza también la figura de narrador. A este respecto, conviene subrayar la frecuente aparición de comentarios metalingüísticos en la voz narrativa: reflexiones acerca del lenguaje científico de algunos personajes, valoraciones de los giros de otros e, incluso, excursos acerca de la insuficiencia expresiva del lenguaje y la inevitable distorsión de la experiencia en el proceso verbalizador. Así, al leer las cartas de su padre encontradas en el trastero, pondera las virtudes de su estilo, si bien critica la discontinuidad de su contenido:

El estilo epistolar de mi padre era bastante primoroso, aunque no así el flujo narrativo. Perdía el hilo con regular frecuencia y podía mezclar - por ejemplo- la descripción minuciosa de un paisaje con alguna casi ininteligible reflexión sobre su salud, referida sobre todo a un estado depresivo que se le acentuaba invariablemente por las noches. (1992: 75)

El interés de esta cita reside no sólo en la descripción de los rasgos del estilo paterno, sino en lo que se sugiere implícitamente acerca de las similitudes entre el padre y el hijo. Incluso las referencias al estilo parecen ajustarse también al discurso del narrador: esa mezcla de primor estilístico y cierta confusión en la trama argumental.

La relación entre narrador y referencia plantea también aspectos clave de esa estructura conocida como lector implícito. En primer lugar, esta voz narrativa única domina el relato con su perspectiva homodiegética. Sin embargo, el hecho de tratarse de una sola instancia narrativa no puede ocultar la evidencia de que, en realidad, el lector encuentra una sucesión de perspectivas diferentes vinculadas al avance del tiempo de la enunciación. Así, el lapso entre el momento evocado y el de la escritura implica una modificación de la perspectiva del narrador:

He narrado ese pronóstico tal como lo barrunté anoche, pero ahora, a medida que lo transcribo, se me han ido agregando a esa penumbra imaginativa algunas luces. (1992:134)

De hecho, la propia escritura activa las sensaciones vividas en el tiempo del enunciado: 
Incluso ahora, mientras rememoro por escrito ese episodio, vuelvo a tener la evidencia de que unas porciones distintas de miedo empiezan a diseminarse en mi interior. (1992:117)

Conviene tener presente, por tanto, la constatación de que, si bien se trata de un narrador único, esa figura recoge puntos de vista distanciados en el tiempo, de modo que el resultado final resulta más complejo.

Asimismo, el narrador añade, cuando lo considera necesario, otras perspectivas secundarias, por lo que el efecto de contrapunto queda textualmente garantizado. Así, introduce la perspectiva de Jesús Verdina en el relato de su curioso accidente o el punto de vista de Elvira y Marcela sobre la muerte de Orozco, entre otros muchos ejemplos. Ahora bien, estas incorporaciones se integran en un discurso narrativo en el que predomina la focalización del protagonista.

La complejidad del narrador aumenta con la constatación de su limitado grado de conocimiento, que oscila entre los modelos de equisciencia y deficiencia cognoscitiva. El propio narrador pone de relieve las dificultades de su tarea, determinadas por los problemas del conocimiento de la realidad, la expresión de los hechos y su interpretación. Estas dificultades consisten no sólo en la indecisión acerca de la consistencia de la materia vivida, sino también en una cierta incapacidad para ajustar el discurso convenientemente:

Todo esto ocurrió hace unos veinte días y hasta ahora no he tenido ánimos ni ganas de contarlo. Tampoco estoy muy seguro de estar transcribiéndolo con suficiente exactitud o sin olvidar algo que muy bien tenía el valor de una clave. (1992: 149)

De ahí la dificultad a la hora de marcar los límites relativos a la coherencia narrativa, por lo que el reconocimiento de las quiebras del modelo plantea ciertas dudas.

Por otra parte, la actitud del narrador ante los personajes y los acontecimientos contribuye a la caracterización de la voz narrativa. Interesa, a este respecto, la combinación de discurso interior y exterior, y el uso de la caricatura como elemento distanciador ante determinados personajes. Asimismo, conviene añadir la combinación en el relato de diversos tonos, entre los cuales destacan el tratamiento deformador de la realidad, el subrayado lírico de la historia y la deriva reflexiva en torno a la sustancia narrativa y los personajes. Sucede de esta manera con Gabriela Vinagre, cuyo retrato subraya su fealdad:

Era una mujer cenceña y medio deforme, a la que recordaba de siempre con la misma edad incierta y la misma costra de afeites cubriéndole la agrietada máscara del rostro. Llevaba un nardo enhiesto sobre el rodete y aparecía envuelta en un pañolón inmundo. Ya retirada desde hacía años de sus más propios comercios, seguía actuando de experta en tercerías y comisionista de improvisadas componendas callejeras. (1992: 118-119).

Todo ello, en definitiva, compone un panorama desconcertante, una interpelación continua al lector.

Desde el punto de vista pragmático, algunos detalles determinan también los rasgos del lector implícito. En efecto, ciertos datos textuales permiten reconocer la imagen pública del autor en el texto, mecanismo que actúa como una marca de la casa y condiciona, desde la perspectiva del lector, la inserción del relato en el conjunto de la obra na- 
rrativa de Caballero Bonald. Esta huella se aprecia en la consignación de problemas íntimos presentes en otras novelas, como la cuestión de las relaciones familiares obsesivas o el análisis de una psicología torturada. También el lector puede reconocer algunos rasgos ideológicos recurrentes: el aprecio por los vencidos de la guerra civil, la fascinación por la naturaleza y la defensa de formas tradicionales respetuosas con el medio natural. Asimismo, otros aspectos, como la presencia del espacio sanluqueño, la cuestión de la escritura o el aprecio por la cultura del vino permiten al lector la identificación del mundo narrativo de Caballero Bonald.

También en el horizonte de expectativas se observan elementos de lector implícito (JAUSS, 1970). Por una parte, las declaraciones del escritor subrayan el trasfondo biográfico de la historia, detallando el proceso de isquemia padecido por el autor. Con cierta reiteración, Caballero Bonald reflexiona sobre las complejas relaciones existentes entre el recuerdo y la creación literaria. Esto es particularmente notable en esta novela, que transforma una experiencia dolorosa del escritor relacionada con un proceso de insuficiencia circulatoria cerebral. A causa de esta alteración física, el autor padeció trastornos del sueño, recuerdos falsos y distorsiones en la percepción de la realidad, hasta el punto de sentirse desdoblado en otro y verse como un personaje literario:

Y empecé a contar todo eso, claro que soldándolo a otras peripecias puramente imaginativas. Ocurrió además que muchas de las cosas que yo me había inventado resultaron ser las más reales. Quiero decir que viví una experiencia inversa: conocer en la vida real a unos personajes que yo concebí previamente en la novela. Un asunto éste - dicho sea de pasada - bastante inquietante. (1999: 364-365)

Así pues, la realidad más prosaica encierra una virtualidad creativa que el escritor aprovecha, poniendo en marcha de esta manera un mecanismo con resultados sorprendentes incluso para el propio autor. No obstante, Caballero Bonald subraya la distancia entre la experiencia que origina el proceso de escritura y el resultado, una obra de ficción que guarda inesperadas conexiones con la realidad.

En cuanto a las indicaciones paratextuales, esto es, el conjunto de informaciones que acompañan al texto y orientan su interpretación, en la edición de Anagrama de 1992 destacan algunos elementos: la ilustración de Patinir, que refuerza la confusión del título, la inclusión de la obra en una colección de narrativa de ficción y los comentarios de la contraportada. En estas observaciones, de cierta incidencia en la configuración del horizonte de expectativas, destaca la llamada a una recepción diferente. Tras una breve indicación de la trama, el comentarista editorial subraya la tensión entre lo cotidiano y lo irracional como una de las claves del relato. Así, se sugiere, el lector se ve emplazado a implicarse más en la lectura, ante los desafíos planteados por la historia. Se trata, en definitiva, de orientar al posible lector sobre la necesidad de una recepción más activa.

En especial, el comentarista pone de relieve un aspecto medular para la recepción, la consideración del carácter ficcional de la obra y su clasificación como novela. Dentro del habitual estilo elogioso, la valoración de la contraportada pondera la potencia imaginativa de esta ficción, que acaba considerando como una «extraordinaria novela» que supone el regreso «al territorio de la ficción» de uno de los «mayores escritores españoles contemporáneos». 
En cuanto a la crítica, el lector encuentra en ella la confirmación del carácter ficcional del relato. Es algo que acaba corroborándose en la lectura, pues no hay identidad expresa entre protagonista, narrador y autor, ni está justificada textualmente la atribución automática de las anécdotas relatadas al novelista.

La crítica pone de relieve la trasposición ficcional de un incidente biográfico, lo que redunda en la construcción de un sentido de la realidad que incorpora sus aspectos más contradictorios e inverosímiles. El escritor transforma la realidad al convertir la experiencia vital en construcción literaria. Según A. Ortega, no es ajeno este proceso a la influencia de una obra muy del agrado de Caballero Bonald, el Persiles de Cervantes:

(...) nos remite de inmediato a la fertilidad imaginativa, a la sugestión de ese espejismo genial cervantino, que es asumido aquí en la medida en que asistimos a una historia que se narra desde un presente que rechaza la realidad por ilusoria, al tiempo que celebra la ilusión por real, porque al final la aventura será la del espacio y el origen recobrados por la imaginación. (ORTEGA, 1992: 55)

La ampliación del concepto de realidad encaja, por tanto, dentro de la tradición del último Cervantes, por quien el escritor jerezano muestra especial predilección. Lo maravilloso, sin embargo, tiene un origen concreto, el mundo marismeño, un espacio que desafía las medidas convencionales y acerca al autor a lo inverosímil.

La ambigüedad, la estructura episódica y el estilo constituyen aspectos muy valorados de esta obra. Constituyen, por supuesto, un desafío para el lector, en la medida en que exigen una lectura interpretativa. El párrafo final del artículo de Valls relaciona estos rasgos con el sentido último de la obra:

Paradójicamente, sólo entre esta confusión y este caos - y a través de la escritura, como hemos dicho - logra el protagonista hallar un poco de claridad, empieza a distinguir «el límite todavía nebuloso que separa lo razonable de lo quimérico» (p.186), consigue conocerse un poco mejor, concluir el aprendizaje vital que se nos narra. Pero es sólo tras ese simbólico episodio en el que se le cae la librería encima (p.296), cuando quizá empieza a tener la certeza de que en las raíces, en lo telúrico, está la esencia, el conocimiento. (VALLS, 1993: 28)

El misterio, lo irracional y la confusión, factores que justifican la mención del campo de Agramante, alcanzan en el relato un relieve particular, lo cual implica necesariamente al lector, cuyo cometido textual gana en relevancia, hasta el punto de verse forzado a adoptar un papel de detective y psicólogo (WOOD, 1994:124). Precisamente, el proceso patológico vivido por el protagonista acaba afectando al lector, inmerso en la vecindad con lo irrazonable, entre la cotidianidad y la alucinación. Éste es el meollo de la cuestión y en él parece hallarse el sentido último de la ficción, en palabras de Gutiérrez Carbajo:

En medio de estos dos espacios narrativos - el ilusorio de la infracción de la lógica y el fidedigno de una localizable ciudad bajoandaluza - aparece y desaparece una serie de personajes que, sin rebasar del todo la frontera de lo insólito, participan de una inquietante complicidad con ese narrador-protagonista, que se nos muestra extraviado entre la equívoca memoria y el presente enfermizo; un narrador-protagonista que viene a ser también como el 
intérprete de un mundo a la vez elemental y caótico, de una suerte de parodia social donde el concepto de ficción adquiere su más poderosa relevancia imaginativa. (GUTIÉRREZ CARBAJO, 2005: 18-19)

\section{A MODO DE CONCLUSIÓN}

Llegados a este punto, es el momento de valorar en qué sentido puede considerarse esta novela como una obra singular dentro de la producción narrativa del escritor jerezano y por qué exige una recepción más activa del lector.

Por una parte, la adopción, en clave ficcional, de las técnicas de la escritura del yo, a medio camino entre la autobiografía y el dietario, pone de relieve en Campo de Agramante un factor destacado en la evolución del escritor, que confirmarán las «novelas de la memoria», Tiempo de guerras perdidas (1995) y La costumbre de vivir (2001): la renovación del género novelístico se verifica en la quiebra de los límites genéricos.

Por otra parte, si bien Campo de Agramante mantiene un trasfondo histórico y social común a relatos anteriores y una elaboración estilística muy representativa del autor, la propuesta de lectura de esta novela desvía la atención hacia el mundo interior del protagonista, la constatación del frágil concepto de realidad, la dificultad de su conocimiento y las problemáticas relaciones familiares.

Esta narración provoca, efectivamente, una cierta desconfianza ante el carácter dudoso de las percepciones humanas, perplejidad que el lector comparte frente a numerosas situaciones vividas por el protagonista. Sus vivencias, sueños, anticipaciones, comentarios...enfrentan al lector ante los perfiles paradójicos de la vida. A este respecto, la secuencia final del hundimiento de la biblioteca y su percepción anticipada, que implican el rebrote de un trastorno aparentemente superado, corrobora la obstinada presencia del misterio en la realidad más cotidiana. En definitiva, todos los elementos constructivos de este relato interpelan al lector, quien debe abrirse paso en una historia que, no en vano, se titula Campo de Agramante.

\section{REFERENCIAS BIBLIOGRÁFICAS}

Bobes Naves, M. C. (1993): La novela, Madrid, Síntesis.

Caballero Bonald, J. M. (1992): Campo de Agramante, Barcelona, Anagrama.

- (1999): Copias del natural, Madrid, Alfaguara.

GutiérRez Carbajo, F. (2005). «Introducción». En Caballero Bonald, J. M.: Dos días de setiembre, Madrid, Castalia.

ISER, W. (1970): «La estructura apelativa de los textos». WARNING, R., editor (1989): Estética de la recepción, Madrid, Visor, pp. 133-148.

- (1972): «El acto de lectura: un enfoque fenomenológico». MAYORAL, J. A., editor (1987): Estética de la recepción, Madrid, Arco-Libros, pp. 215-243.

JAUSS, H. R. (1970): La historia de la literatura como provocación, Barcelona, Península (2000). Ortega, A. (1992): «Ocupación de la memoria». El Urogallo, noviembre, p. 55-57. 
Romera CASTILlo, J. et alii (1995): Elementos para una semiótica del texto artístico, Madrid, Cátedra.

VALLs, F. (1993): «Reseña de Campo de Agramante». Ínsula 556, pp. 27-28.

Wood, G. H. (1994): «Reseña de Campo de Agramante». España Contemporánea VII, 2, pp. $122-$ 124. 